\title{
Intervenção da Terapia Ocupacional no Tratamendo de Individuos com Doenças Reumáticas Utilizando a Abordagem da Proteção Articular
}

\author{
Johanna Noordhoek ${ }^{(1)}$, Fabricia Quintão Loschiavo(2)
}

Os impactos e conseqüências de uma doença podem ser descritos de diferentes maneiras. Entretanto, os sentimentos e as reações de cada indivíduo, frente ao processo patológico, não são apenas influenciados pelas condições somáticas, físicas, mas também pela personalidade e circunstâncias sociais ${ }^{(1)}$. Os indivíduos com doenças reumáticas terão graus variados de comprometimento em sua performance nas atividades da vida diária (AVDs), trabalho e lazer, resultando em limitações de seu desempenho e baixa da auto-estima ${ }^{(1)}$.

"A Terapia Ocupacional é uma profissão de saúde que auxilia o indivíduo a recuperar, desenvolver e construir habilidades que são importantes para sua independência funcional, saúde, segurança e integração social"(2). Dessa maneira, visando o alcance de todos esses objetivos, as áreas de abrangência da intervenção terapêutica ocupacional encontram-se centradas nas AVDs, trabalho e lazer, potencialmente prejudicadas em decorrência de processos que interfiram na funcionalidade dos indivíduos. Assim, considerando-se os pacientes acometidos pelas doenças reumáticas como sendo pessoas que apresentam comprometimentos potenciais em suas funções do cotidiano, seria indicado o tratamento terapêutico ocupacional, tanto em acompanhamento individual como em grupo, aliado ao acompanhamento médico e dos demais profissionais da área da saúde.

O método de intervenção grupal é adequado para pacientes com doenças crônicas ${ }^{(1)}$. O conhecimento sobre a doença e os medicamentos, orientações sobre proteção articular (centradas em medidas que objetivam a redução de estresse nas articulações) ${ }^{(1)}$ e sobre a própria postura do indivíduo, proporcionados no trabalho em grupo com os pacientes com doenças reumáticas, fazem com que os indivíduos assumam um papel mais ativo, na medida em que mobiliza a participação e controle diante dos sintomas da doença, atuando, assim, diretamente no incremento da qualidade de vida(3).

Essa abordagem terapêutica de proteção articular surgiu em 1965, a partir de terapeutas ocupacionais e cirurgiões de mão, e foi desenvolvida com o objetivo de minimizar as conseqüências da artrite reumatóide (AR). Em 1970, essa abordagem foi disseminada, e começou a ser empregada em grupos de orientação para pacientes ${ }^{(1)}$. A metodologia tem como objetivos: fornecer informações básicas sobre as doenças reumáticas; esclarecer e apontar possibilidades de gerenciar e controlar a dor, a instabilidade articular, a fraqueza muscular e a fadiga; evitar a dor e o estresse articular na execução das atividades diárias. Dessa maneira, os princípios das orientações de proteção articular são: balancear os períodos de atividade com descanso, visando assim à conservação de energia; evitar posições e movimentos que propiciem o surgimento e/ou agravamento de deformidades; respeitar a dor; usar as articulações mais fortes, sempre que possível; evitar utilizar a mão para a realização de preensão de força; realizar um programa de exercícios regulares para manutenção da força muscular e amplitude de movimento, evitando-se assim a rigidez articular; realizar um planejamento prévio das tarefas diárias, evitando-se a fadiga e permanecer em uma posição estática durante muito tempo ${ }^{(1)}$. Com a implementação dessas orientações, objetiva-se a manutenção da integridade articular, redução da dor e da fadiga ${ }^{(4)}$.

Objetivando uma maior compreensão por parte dos pacientes atendidos no setor de Terapia Ocupacional no Ambulatório Bias Fortes, do Hospital das Clínicas da Universidade Federal de Minas Gerais, e no projeto de extensão "Programa de Orientação aos Indivíduos acometidos por Doenças Reumáticas”, do Ambulatório Borges da Costa dessa mesma instituição, bem como uma

1. Terapeuta ocupacional, professora do Departamento de Terapia Ocupacional da Escola de Educação Física, Fisioterapia e Terapia Ocupacional da Universidade Federal de Minas Gerais (UFMG), Belo Horizonte, MG, Brasil. Coordenadora do projeto de extensão "Programa de Orientação aos Indivíduos Acometidos por Doenças Reumáticas”.

2. Terapeuta ocupacional da Universidade Federal de Minas Gerais (UFMG), Belo Horizonte, MG, Brasil. 
maior viabilidade prática, foi elaborada uma Cartilha de Orientação aos Indivíduos Acometidos por Doenças Reumáticas ${ }^{(5)}$. Esse material tem como objetivos o fornecimento de uma breve explicação sobre as doenças reumáticas e de orientações relacionadas à proteção articular durante as atividades de trabalho, lazer e descanso. Para tanto, constam na cartilha diversos desenhos, em conformidade com as figuras apresentadas abaixo, indicando as maneiras erradas e ressaltando as formas adequadas de utilizar as articulações, tendo-se sempre em vista os princípios de proteção articular, explicitados anteriormente.

\section{Errado}
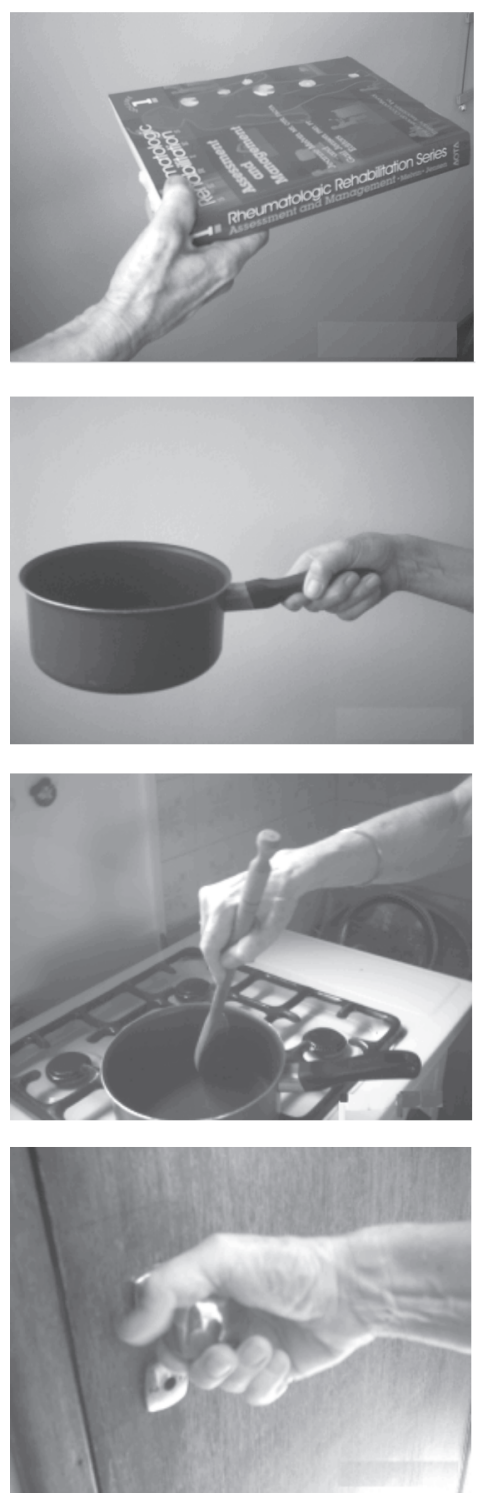

Dessa maneira, a intervenção terapêutica ocupacional, nesta abordagem, centra-se no nível primário de atenção à saúde, ou seja, na sua promoção, na medida em que os indivíduos, mesmo já com deformidades instaladas e/ou em processo de instalação, apreendem novas e corretas formas de lidar com o seu meio (prevenindo, assim, a instalação de outras deformidades) e tornam-se aptos a assumir um papel ativo e responsável, resgatando assim o seu potencial de saúde. Tais fatores exercem influência direta no incremento dos aspectos relacionados à qualidade de vida dos pacientes.

\section{Correto}
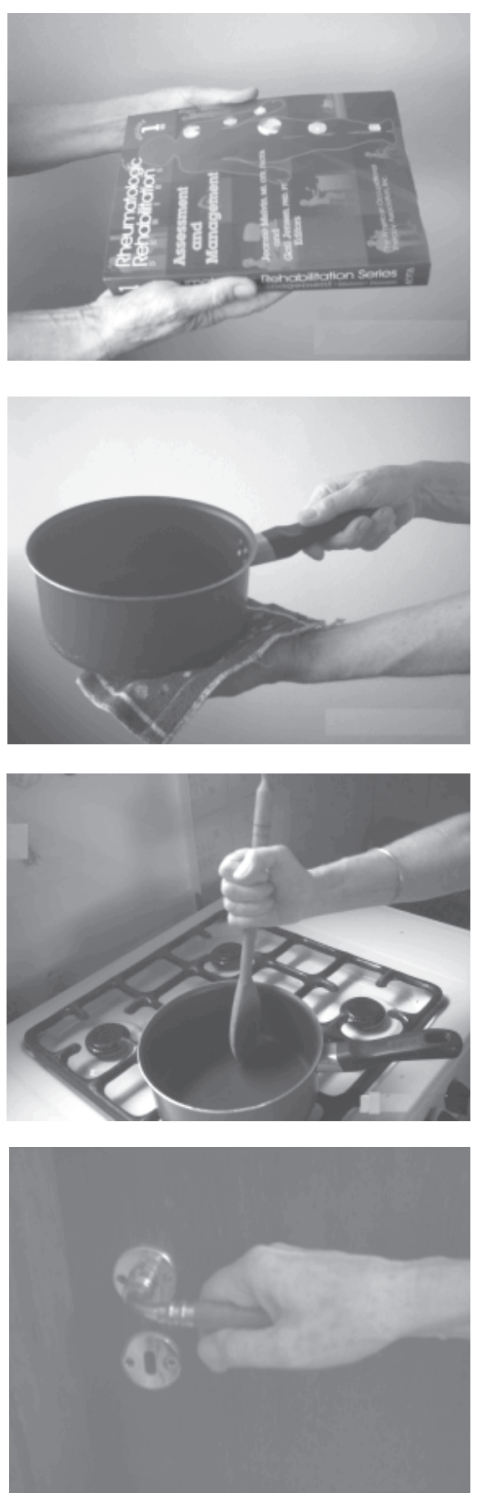


\section{Errado}
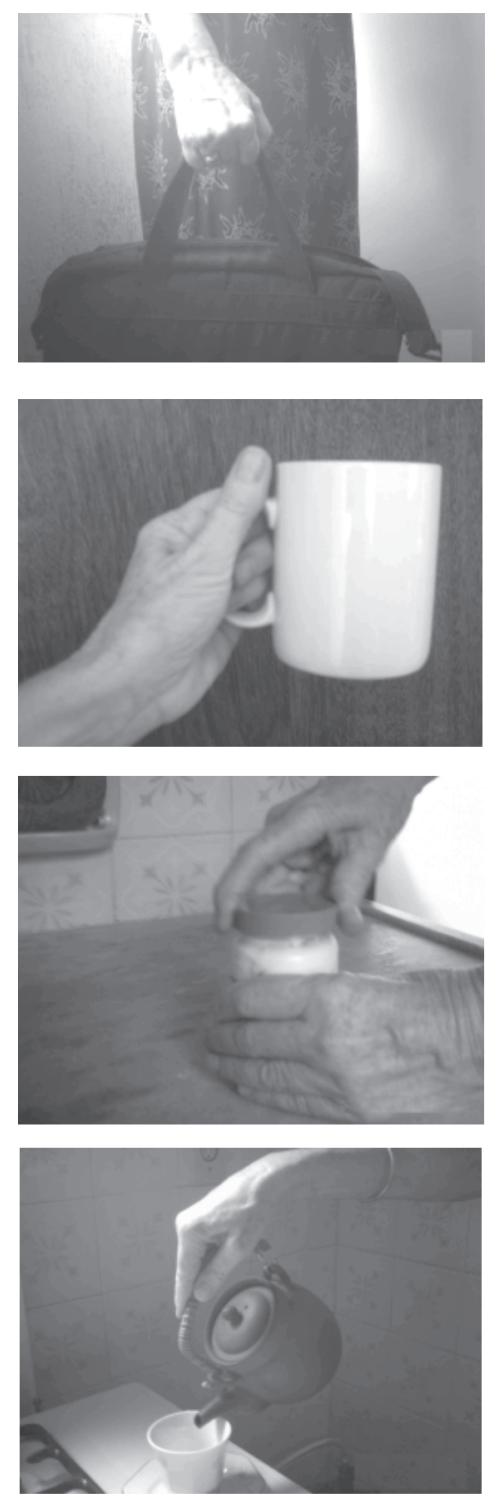

Correto
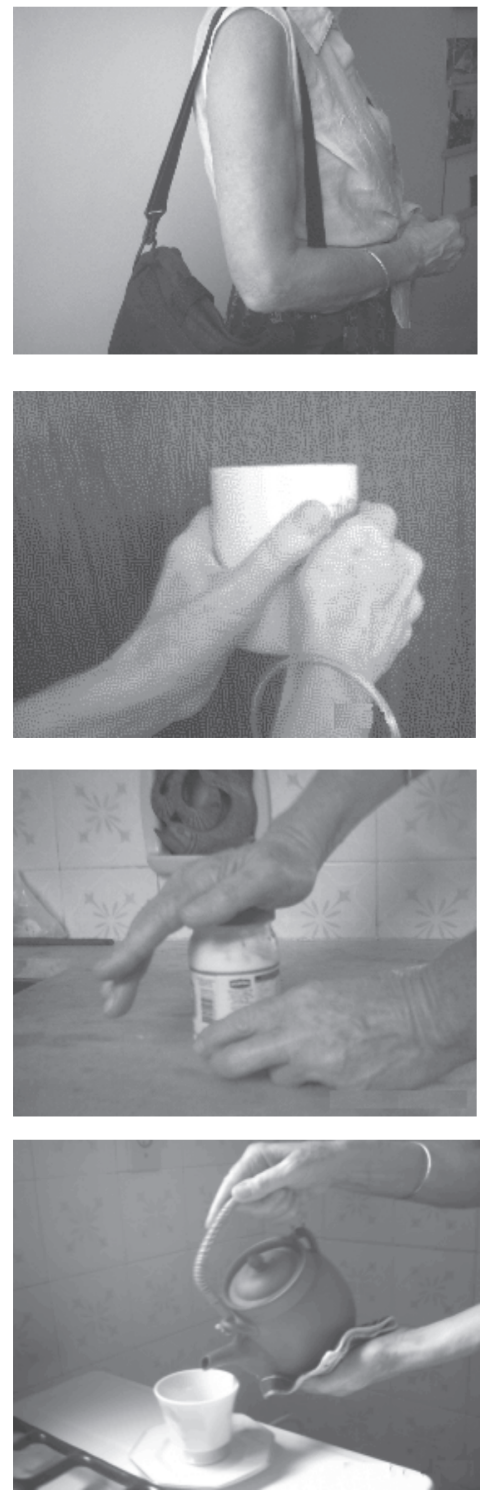

\section{REFERÊNCIAS}

1. Nordenskiöld U, Althoff B, Hansen A: Joint Protection - for Activeling GUIDE. Stockholm: The Swedish Rheumatism Association, 1994.

2. American Occupational Therapy Association (AOTA). [Disponível em: <http://www.aota.org>. Acesso em: 20 maio 2004.]

3. Helliwell PS, O’Hara M, Hoklsworth J, Hesselden A, King T, Evans P: A 12-month randomized controlled trial of patient education on radiographic changes and quality of life in early rheumatoid arthritis. Rheumatology 38: 303-8, 1999. [Disponível em: < http:// rheumatology.oupjournals.org/cgi/reprint/38/4/303>. Acesso em: 15 maio 2004.]

4. Palmer P, Simons J: Joint Protection: A Critical Review. British J Occupational Therapy 54: 453-8, 1991.

5. Noordhoek J, Matias FM: Cartilha de Orientação aos Indivíduos Acometidos por Doenças Reumáticas. Belo Horizonte: Editora Gráfica Silveira, 2003. 